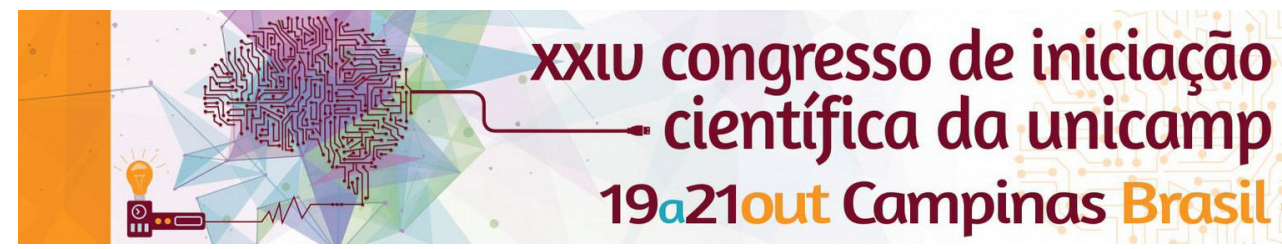

\title{
Implantação de um Programa de Atividade física para a Promoção de Saúde e Qualidade de Vida.
}

\section{Janini L. Diniz*, Ademir De Marco}

\section{Resumo}

Esta pesquisa consiste na Implantação de um Programa de Atividade Física na Promoção da Saúde e Qualidade de Vida das professoras da DedIC - UNICAMP no espaço CECI (Centro de Convivência Infantil/DedIC/UNICAMP), nas quais aulas do Método Pilates, condicionamento físico e alongamento foram ministradas para o grupo experimental inicial composto por $(\mathrm{N}=8)$. O objetivo principal desta pesquisa é o de mensurar como esse programa pode influenciar a Qualidade de Vida e Estilo de Vida das professoras. Estão sendo utilizados instrumentos avaliativos como Whoqol bref, Testes de Capacidades Físicas com estratégia de pré e de pós teste a fim de mapear possíveis benefícios para a Qualidade de Vida das participantes. Os resultados preliminares indicam que o tempo de Atividade Física realizada não foi suficiente para demonstrar melhoria nas capacidades sendo necessário um intervalo maior do que oito semanas. Assim,este projeto terá continuidade no próximo semestre, com maior adesão das professoras da DEdIC/UNICAMP.

\section{Palavras-chave:}

Qualidade de Vida, Promoção da Saúde, Atividade Física. Introdução

A "Organização Mundial de Saúde" (OMS) define a saúde como "um estado de completo bem-estar físico, mental e social e não somente ausência de afecções e enfermidades" Para Gutierrez (1994, apud Gutierrez, M. et al., 1997), promoção da saúde é o conjunto de atividades, processos e recursos, de ordem institucional, governamental ou da cidadania, orientados a propiciar a melhoria das condições de bem estar e acesso a bens e serviços sociais. A criação de espaços para proporcionarem saúde na escola, lazer, trabalho, são necessários para a promoção da saúde, um trabalho intersetorial com os profissionais da Educação Física pode auxiliar na melhoria de diversos aspectos cognitivos, psicológico e social, apresentando ação preventiva e educativa visando a melhoria do bem-estar e prevenção e Qualidade de Vida.

\section{Resultados e Discussão}

A partir da carta de Ottawa propostas da criação de espaços que possam possibilitar ambientes favoráveis à saúde no trabalho, escola, e lazer são de responsabilidade indelegável do Estado para suprir serviços de políticas públicas de saúde. Nesta linha o Grupo de Estudos em Educação Física no Desenvolvimento Infantil - GEEFIDI - que atua com a formação continuada de professoras, elaborou esse projeto que visa a Promoção da Saúde. Para obtenção dos resultados foram utilizados instrumentos de mensuração da Qualidade de Vida - Whoqol bref, e testes de capacidades físicas.

Análise Whooqol Bref

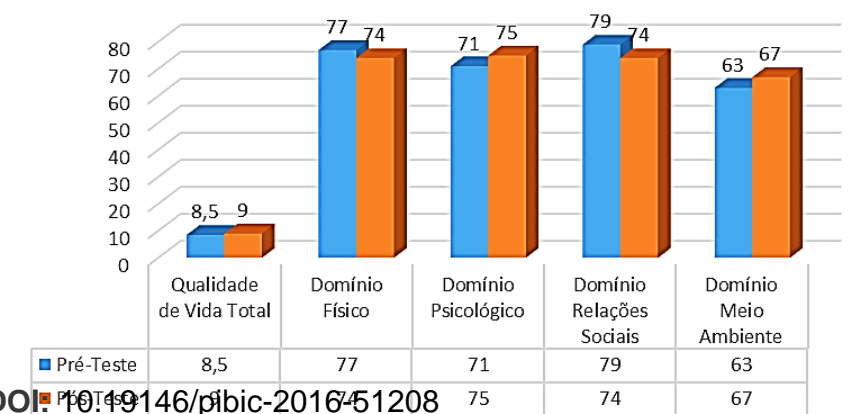

Tabela 1. Teste para verificação de capacidades física.

\begin{tabular}{c|cccc|} 
& $\begin{array}{c}\text { Pré teste } \\
\text { média(DP) }\end{array}$ & $\begin{array}{c}\text { Pós } \\
\text { teste }\end{array}$ & $\begin{array}{c}\mathrm{P} \\
\text { valor }\end{array}$ & $\begin{array}{c}\text { Percentual } \\
\text { aumento }\end{array}$ \\
\hline $\begin{array}{c}\text { Potência de } \\
\text { Membro } \\
\text { superior } \\
\text { (metros) }\end{array}$ & 1,95 & 2,24 & 0,30 & $14,87 \%$ \\
$\begin{array}{c}\text { Potência de } \\
\text { Membro } \\
\text { Inferior } \\
\text { (metros) }\end{array}$ & 0,97 & 1,04 & 0,01 & $7,21 \%$ \\
$\begin{array}{c}\text { Flexibilidade } \\
\text { (centímetro) }\end{array}$ & 24,4 & 22 & 0,23 & $-9,83$ \\
\hline
\end{tabular}

Os dados estão apresentados em média (desvio padrão).

Vemos diferença significativa na potência de membro superior com o treinamento realizado para as professoras, porém, a flexibilidade e potência de membro inferior não houve diferença significativa. Questões sobre Qualidade de Vida devem ser abordadas nesse segundo momento para sensibilizá-las sobre o tema.

\section{Conclusão}

A partir dos resultados obtidos na pesquisa e a confrontação com a literatura, verifica-se que o tempo de Atividade Física realizada não foi suficiente para demonstrar melhoria nas capacidades sendo necessário um intervalo maior do que oito semanas. Assim, em razão destes resultados preliminares esta pesquisa se estenderá por mais um semestre.

\section{Agradecimentos}

Agradeço ao CNPq pela bolsa, minha família e minhas amigas de lar, ao meu orientador, Prof. Dr. Ademir De Marco, aos integrantes do GEEFIDI pela colaboração. Simone Kishimoto e Júlia Barreira pelo apoio acadêmico e a minha instituição de ensino, FEF e UNICAMP.

Gutierrez M et al. Perfil descriptivo-situacional del sector de la promoción y educación en salud: Colombia. In Aroyo HV e Cerqueira MT (eds.), 1996. La Promoción de la Salud y la Educación para la Salud en America Latina: un Analisis Sectorial. Editorial de la Universidad de Puerto Rico. 114 pp. 